Intervention: introduction of bDMARDs and associated publication of bDMARD recommendations in Denmark in 2002.

Statistical analyses: 5-year age- and sex-standardised incidence rates of THR and TKR calculated for incident RA patients diagnosed biannually in 1996-2011, and GPCs. Secular trends in the pre-bDMARD guideline era (1996-2002) were compared with those in the bDMARD period (2003-2016) using segmented linear regression and a 1-year lag period (2002-03). Absolute changes in TKR and THR at the midpoint (February 2007) between guideline implementation and end of study period were estimated.

Results: In total, during 1996 to 2011, 30868 incident RA patients were identified (mean age at diagnosis 58.3 years, 70\% women) and compared with 301527 GPCs. See Table for results.

Table 1. Changes in 5-year incidence rate of total hip (THR) or total knee replacement (TKR) in incident rheumatoid arthritis (RA) patients following introduction of biological DMARDs compared with secular trends in age, sex and municipality-matched general population controls (GPC)

\begin{tabular}{ccccccc}
\hline Cohort & & $\begin{array}{c}n \\
\text { THR/TKR }\end{array}$ & $\begin{array}{c}\text { Baseline incidence } \\
\text { rate/1000 person years }\end{array}$ & $\begin{array}{c}\Delta \text { per year } \\
\text { pre-2002 }\end{array}$ & $\begin{array}{c}\Delta \text { in } \\
\text { level 2003 }\end{array}$ & $\begin{array}{c}\Delta \text { per year } \\
\text { post-2003 }\end{array}$ \\
\hline TKR & RA & 865 & 5.87 & +0.19 & - & -0.20 \\
& GPC & 2438 & 0.42 & +0.21 & - & +0.08 \\
THR & RA & 935 & 8.72 & -0.38 & +2.23 & -0.38 \\
& GPC & 4744 & 2.89 & +0.11 & - & +0.02 \\
\hline
\end{tabular}

Stepwise backward elimination to produce most parsimonious model: $p$-entry $<0.05$ and $p$-exit 0.2. ${ }^{*} \Delta$ per year based on biannual data.

Incidence rate of TKR in newly diagnosed RA patients and matched GPCs

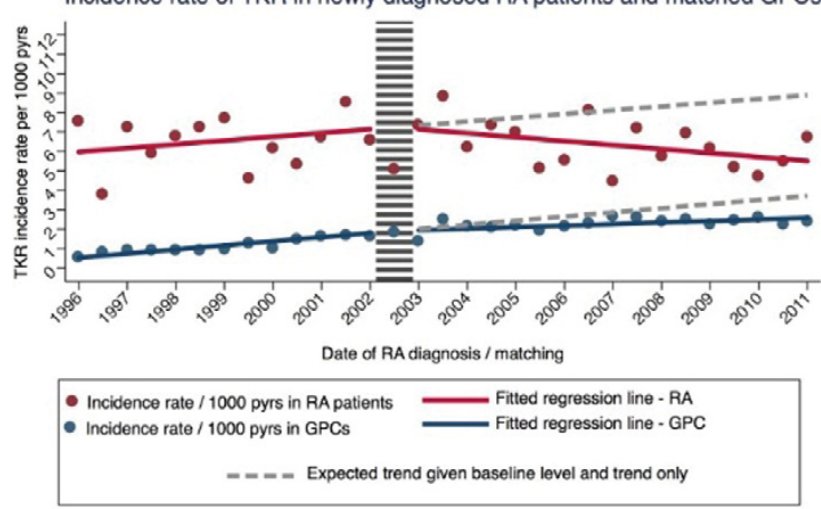

Conclusions: Prior to 2002, the incidence of TKR increased among RA patients, but started to decrease after introduction of bDMARDs and their associated guidelines in 2003 (absolute change -1.8 TKRs/1000 person years in Feb. 2007). In contrast, the incidence of TKR increased among GPCs throughout the entire study period. The incidence of THR increased in GPCs for the entire duration of the study period, whereas there was a downward going trend among RA patients, but with a surprising level increase in 2003. The overall patterns of our findings are in line with those recently reported from England and Wales ${ }^{1}$.

References:

[1] Hawley S, Cordtz R, Dreyer L, et al. The Impact of Biologic Therapy Introduction on Hip and Knee Replacement Among Rheumatoid Arthritis Patients: An Interrupted Time Series Analysis Using the Clinical Practice Research Datalink. Arthritis Rheumatol 2016;68.

Disclosure of Interest: R. Cordtz: None declared, S. Hawley: None declared, D. Prieto-Alhambra Grant/research support from: DPA's group has received unrelated research grants from Amgen and Servier, L. E. Kristensen Speakers bureau: Pfizer, AbbVie, Amgen, UCB, Celgene, BMS, MSD, Novartis, Eli Lilly, Janssen Pharmaceuticals, S. Overgaard: None declared, A. Odgaard: None declared, L. Dreyer: None declared

DOI: 10.1136/annrheumdis-2017-eular.1227

\section{OP0252 RHEUMATOID ARTHRITIS PATIENTS WITH CONTINUED LOW DISEASE ACTIVITY HAVE SIMILAR OUTCOMES OVER 10 YEARS, REGARDLESS OF INITIAL THERAPY}

S.A. Bergstra ${ }^{1}$, R.B. Landewé ${ }^{2,3}$, T.W. Huizinga ${ }^{1}$, C.F. Allaart ${ }^{1} .{ }^{1}$ Rheumatology, LUMC, Leiden; ${ }^{2}$ Amsterdam Rheumatology \& Immunology Center, Amsterdam; ${ }^{3}$ Zuyderland Medical Center, Heerlen, Netherlands

Background: Low disease activity and remission in rheumatoid arthritis (RA) patients is achieved earlier and in higher frequency when the initial treatment includes a combination of methotrexate (MTX) with corticosteroids or a biologic disease modifying anti-rheumatic drug than MTX alone. However, it is unknown whether in patients with early and persistently good response the initial treatment still has an impact on long term outcomes.

Objectives: To compare 10 years disease outcomes of RA patients with persistent low disease activity on MTX monotherapy or on initial combination therapy with infliximab or prednisone and sulfasalazine.

Methods: RA patients with 10 years follow-up from the BeSt study were analyzed. RA patients fulfilling the American College of Rheumatology 1987 criteria with $<2$ years symptom duration were "treated to target" aiming at disease activity score (DAS) $\leq 2.4$, assessed with 3-monthly intervals. Patients in arms 1 and 2 started MTX monotherapy, patients in arm 3 started MTX, sulfasalazine and prednisone and patients in arm 4 started MTX and infliximab. All had DAS $\leq 2.4$ from $t=6$ months until $\mathrm{t}=10$ years and therefore stayed on initial treatment, with patients in arms 3 and 4 tapering to monotherapy within 10 months. Patients in arms 1 and 2 were compared with patients in arms 3 and 4 . Between-group differences over time were compared using (generalized) linear mixed model analyses, for the outcomes DAS, Health Assessment Questionnaire (HAQ), erythrocyte sedimentation rate (ESR), visual analogue scale (VAS) patient global health (range 0-100), percentage patients in remission and drug free remission and percentage patients with Sharp/van der Heijde score progression $\geq 5$.

Results: At $t=10$ years $28 / 247(11 \%)$ patients in arms 1 and 2 had sustained DAS $\leq 2.4$ compared to $68 / 261$ (26\%) patients in arms 3 and 4 . Patients in arms 1 and 2 were less often ACPA positive ( $46 \%$ versus $54 \%, p=0.477$ ), had shorter symptom duration at baseline [median (range) 14 (1-191) versus 18 (4-263) weeks, $p=0.004]$ and less radiologic damage progression after 10 years $[0(0-16)$ versus $2.5(0-26), p=0.014]$ than patients in arms 3 and 4 . No between-group differences were found over time, except for the percentage of patients in drug free remission. Significant group-time interactions were found for DAS, ESR and VAS patient's global health, but not $\mathrm{HAQ}$, percentage remission and percentage drug free remission, with slightly worse results over time for arms 3 and 4 compared to arms 1 and 2 (table 1).

\begin{tabular}{|c|c|c|c|}
\hline & Linear Mixed Model Analyses & $\beta$ & $95 \% \mathrm{Cl}$ \\
\hline \multirow[t]{2}{*}{ HAQ } & Treatment group $p^{*}$ & 0.076 & $-0.066 ; 0.22$ \\
\hline & Time & -0.0034 & $-0.0044 ;-0.0025$ \\
\hline \multirow[t]{3}{*}{ DAS } & Treatment group & 0.031 & $-0.24 ; 0.18$ \\
\hline & Time & .0 .029 & $-0.037 ;-0.021$ \\
\hline & Treatment group"Time & 0.0056 & $0.0012 ; 0.010$ \\
\hline \multirow[t]{3}{*}{ ESR } & Treatment group ${ }^{\circ}$ & -3.30 & $-7.54 ; 0.93$ \\
\hline & Time & -0.19 & $-0.31 ;-0.072$ \\
\hline & Treatment group"Time & 0.11 & $0.041 ; 0.17$ \\
\hline VAS patient global & Treatment group' & -4.07 & $-9.50,1.37$ \\
\hline \multirow[t]{3}{*}{ health } & Time & -0.42 & $-0.57 ;-0.27$ \\
\hline & Treatment group*Time & 0.090 & $0.0048 ; 0.17$ \\
\hline & Genera lized linear mixed model analyses & OR & $95 \% \mathrm{Cl}$ \\
\hline \multirow{2}{*}{$\begin{array}{l}\text { SvdH score } \\
\text { progression }=5\end{array}$} & Treatment group ${ }^{\circ}$ & 0.83 & $0.17 ; 4.01$ \\
\hline & Time & 0.94 & $0.83 ; 1.07$ \\
\hline \multirow[t]{2}{*}{ Remission } & Treatment group ${ }^{\circ}$ & 0.58 & $0.32 ; 1 . \infty 8$ \\
\hline & Time & 1.04 & $1.03 ; 1.04$ \\
\hline \multirow[t]{2}{*}{ Drug free remis sion } & Treatment group & 0.14 & $0.033 ; 0.61$ \\
\hline & Time & 1.06 & $1.03 ; 1.08$ \\
\hline
\end{tabular}

"Difference between treatment groups, MTX monotherapy responders as reference group, SE = standard error, $95 \% \mathrm{~d}=95 \%$ confidence interval

Conclusions: More patients achieved continuous low disease activity on prednisone or infliximab combination therapy tapered to MTX monotherapy than on MTX monotherapy, but there appear no additional benefits of combination treatment strategies for patients who have sustained DAS $\leq 2.4$. Regardless of initial induction therapy, those who remain in low disease activity have similar long term outcomes, with only the proportion of patients in drug free remission being higher in the MTX monotherapy group. These results strongly suggest that rapid achievement of remission/LDA itself, rather than how you achieve it, is crucial for determining long-term outcome in RA.

Disclosure of Interest: None declared

DOI: 10.1136/annrheumdis-2017-eular.1707

\section{OP0253 PASSIVE SMOKING IN CHILDHOOD AND HISTORY OF CHRONIC DIARRHEA INCREASES THE RISK OF DEVELOPING RHEUMATOID ARTHRITIS (RA)}

R. Seror ${ }^{1,2}$, G. Gusto ${ }^{3}$, M.C. Boutron-Ruault ${ }^{3}$, X. Mariette ${ }^{1,2} .{ }^{1}$ Rheumatology, Hopitaux Universitaires Paris Sud; ${ }^{2}$ INSERM U1184, Université Paris-sud, le Kremlin-Bicetre; ${ }^{3}$ Centre de recherche en epidemiologie et santé des populations, Inserm U1018, Villejuif, France

Objectives: To analyse the impact of active and passive smoking and intestinal transit disorders on the risk of incident RA

Methods: This study is based on the French E3N cohort ("Etude Epidémiologique auprès de femmes de l'Education Nationale"), which included 98,995 women volunteers born between 1925 and 1950 and prospectively followed since 1990 . Eleven self-administered questionnaires were sent to the participants between 1990 and 2014 to collect medical, demographic, environmental and hormonal data and dietary habits. The diagnosis of RA was collected on 2 successive questionnaires. Cases were considered certain if having declared RA and had taken a RA specific medication (methotrexate, leflunomide or biologic) since 2004 (period from which drug reimbursement data was available). Only incident and certain cases were included. Women were excluded if they had an inflammatory bowel disease and/or no information on their smoking status. Passive smoking was assessed by the following question: "When you were children, did you stay in a smoky room?". Patients were considered exposed if the answer was "yes, a few hours, or yes, several hours a day". The usual intestinal transit, reported by women prior to RA diagnosis (on average 10 years), were classified as normal 